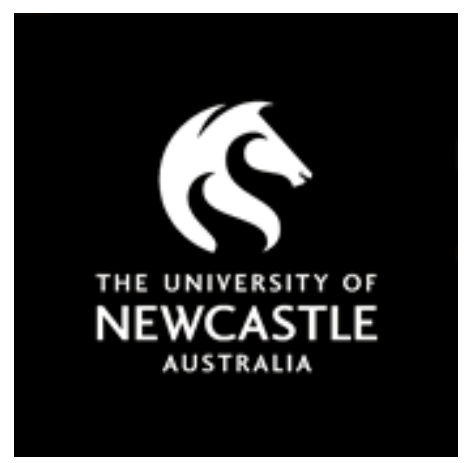

\title{
NOVA
}

University of Newcastle Research Online

nova.newcastle.edu.au

Hung, Yu-Chen; Song, Liang; Chao, Chih-Wei (Fred); Guan, Chong. "Love at first sight: the effect of presentation order on evaluation of experiential options in luxury tour package", Published in the Journal of Business Research Vol. 81, Issue December 2017, p. 181-191. (2017).

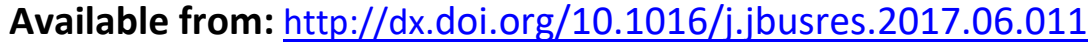

(C) 2017 Elsevier. This manuscript version is made available under the CC-BY-NC-ND 4.0 license http://creativecommons.org/licenses/by-nc-nd/4.0/

Accessed from: http://hdl.handle.net/1959.13/1352215 


\title{
Love at First Sight: The Effect of Presentation Order on Evaluation of Experiential Options in Luxury Tour Packages
}

\author{
Yu-Chen Hung \\ Sim University, Singapore \\ 491 Clementi Road, Singapore 599491 \\ Phone:+65 62485978 \\ ychung@unisim.edu.sg \\ Liang Song \\ Beijing International Studies University, China \\ 1 Ding Fu Zhuang Nan Li, Beijing 100024 \\ Phone: +86 15010625297 \\ liangsong@u.edu.sg \\ Chih-Wei (Fred) Chao \\ (Corresponding author) \\ The University of Newcastle, Callaghan, Australia \\ SR 113 Callaghan NSW 2308 \\ Phone: +61 249216389 \\ Fred.Chao@newcastle.edu.au \\ Chong Guan \\ Sim University, Singapore \\ 491 Clementi Road, Singapore 599491 \\ Phone:+65 62486123 \\ guanchong@unisim.edu.sg
}

Yu-Chen Hung is a lecturer of Business School, Sim University, Singapore, +65-62485978, ychung@unisim.edu.sg. Liang Song is a lecturer of School of Tourism Management, Beijing International Studies University, Beijing 100024, China, +86-15010625297, liangsong@u.edu.sg. Chih-Wei Chao is a lecturer of Newcastle Business School, The University of Newcastle, Callaghan, NSW 2308, Australia, +61-2-49216389, Fred.Chao@newcastle.edu.au. Chong Guan is a senior lecturer of Business School, Sim University, Singapore, +65-62486123, guanchong@unisim.edu.sg. The authors thank the editor, associate editor, and reviewers for their invaluable feedback during the review process. 
This study examined how serial order and information format jointly determine consumers' preferences of tour packages. The results showed that the option viewed first in a sequence was preferred (vs. not preferred) when the information format facilitated (vs. inhibited) narrative processing. Preference shifts to the first viewed option due to narrative processing was prominent among consumers with defensive attitudes to self-threats and in circumstances where the first option was challenged by an attractive alternative. Three experiments were conducted and showed that narrative processing enhanced attachments to the first option if consumers simulated the experience, which in turn motivated them to be consistent in subsequent evaluations. Managerially, these findings suggest that in addition to emphasizing the importance of occupying the first position in a series of advertisements and products, marketers should also facilitate experience simulations rather than focusing solely on the attributes of luxury tours.

Keywords: Serial order, mental simulation, narrative persuasion, experiential products, option attachment, leading option 


\section{Love at First Sight: The Serial Order Effect on the Evaluation of Experiential Options in Luxury Tour Packages}

\section{INTRODUCTION}

Global consumers' increasing affluence is stimulating the rapidly growing luxury travel industry. From 2011 to 2015, the Compound Annual Growth Rate (CAGR) for luxury travel was $4.5 \%$, a figure that exceeded the GACR of $4.2 \%$ for overall travel (Dykins, 2015). The continuing growth in luxury travel highlights two emerging trends. First, consumers in the luxury tourism segment are increasingly seeking a relevant, personal, and exclusive experience rather than material possessions (American Express, 2015). Consequently, marketers need to stimulate consumers' imaginations when communicating the experiential value of leisure activities (Lonsway, 2013; Schmitt, 1999). Second, consumers are increasingly turning to online platforms (e.g., hotel websites and Online Travel Agencies (OTAs)) to search, plan, and book their travel packages (Google, 2014; Xiang, Wang, O’Leary, \& Fesenmaier, 2015). The marketing communication process has gradually moved from offline to online. In the United States (US), 53\% of travel bookings are being completed online (King, 2014). These shifts pose challenges for practitioners and academics; thus, it is imperative that the factors shaping consumers' decision-making processes for experiential services be analyzed.

One ubiquitous element in the online environment is the serial order of marketing stimuli. For example, after a consumer books airline tickets online with Emirates, a few recommended tours are presented sequentially. The presentation order of the tours provides visual cues that guide individuals to view these options in order. Eye tracking studies have shown that consumers scan thumbnails (i.e., miniature product images) on commercial 
websites in an order that reflects their dominant reading direction (e.g., left-to-right and topto-down) (Shun, Chau, \& Tsunhin, 2007). Further, most existing click-through models for advertisement positions follow the sequential search framework under which users browse information from top to bottom in a linear fashion (Chan \& Park, 2015). The top-most advertisement, typically viewed first by consumers, is the most likely to be clicked, preferred, and purchased (Agarwal, Hosanagar, \& Smith, 2011).

Previous research has suggested that marketers can use the serial order effect to strategically promote featured experiential services. However, before this can be achieved, two uncertainties need to be resolved. First, the impact of the serial order effect on preference judgments has been examined extensively in the context of non-experiential products (Houston, Sherman, \& Baker, 1989, 1991; Mantel \& Kardes, 1999), and has welldocumented moderators (Hogarth \& Einhorn, 1992; Jones \& Goethals, 1987). However, little research has been conducted on the impact of the order effect on the evaluation of experiential options. One relevant work on experiential products by Biswas, Grewal, and Roggeveen (2010) showed a recency effect in product sampling. They argued that the sensory input from and affective responses to a last option have a stronger impact than earlier options. Specifically, they contended that due to memory salience, viewers prefer the last option viewed when all options offer a positive experience. They further suggested that the sensory input from the earlier viewed options, including the first option, might decay in memory, lessening the impact on choice. However, references to direct experiences are not available when people choose to travel to new destinations. Thus, it is not yet known how serial order effects the evaluation of experiential options when individuals have no sensory input from a direct experience.

The second uncertainty arises because service providers may choose to present information differently. For example, service providers may choose to communicate the 
experiential values of their services, and thus present information in a way that facilitates experience simulation. Alternatively, other service providers may encourage consumers to be analytical, and thus present information in a way that facilitates comparisons across attributes. However, if consumers have no direct experiences to which they can refer, the serial order effect may depend on the way in which marketers present the information.

This study sought to examine the connection between serial order and information format for experiential services when direct experiences were not available at the time of decision making. Drawing on narrative transportation theory (Green, 2008) and option attachment (Carmon, Wertenbroch, \& Zeelenberg, 2003), this study proposed that the serial order effect would depend on the way in which the tour information was described. Further, it was anticipated that individuals would favor the first tour package they viewed over later viewed counterparts, if the description fostered narrative processing, or encouraged incoming information to be thought of in a story-like manner (Ardelet, Slavich, \& de Kerviler, 2015; Escalas, 2004, 2007). Narrative processing predisposes individuals to experience the self as the protagonist, navigating through described episodes (Kerby, 1991; Polkinghorne, 1991), and thus entails vivid sensory experiences (Taylor, Pham, Rivkin, \& Armor, 1998), strong affective responses (Green \& Brock, 2000; Kim, Lloyd, \& Cervellon, 2016), and a sense of relation to self (Escalas, 2004). This sense of relation to self (also referred to as self-product attachment) (Carmon et al., 2003) should motivate consistent evaluations in support of the option to which the individual attaches, resulting in greater preference toward the attached option (in this case, the first viewed tour package).

Three experiments were conducted to test this proposition. Collectively, the results of the experiments showed that individuals' preferences shift toward the first option (rather than the last option) viewed when the information predisposes (vs. inhibit) them to simulate an experience in a narrative format. This preference shift occurred because the narrative 
processing elicited a greater sense of attachment to the first option. Such a shift becomes prominent when individuals hold defensive attitudes toward self-threats, or when competition arises that challenges the attached option. Overall, these studies showed that narrative processing entailed the primacy effect, as a greater option attachment was formed to the first option in the sequence of experiential options.

This study contributed to theoretical understandings of the serial order effect, option attachment, and narrative processing. It examined the serial order effect on indirect (rather than direct) experiences. The study also extended the literature on affective-based process based on attachment. Further, it expanded understandings of option attachment that has been shown to evolve when individuals' elaborate options closely (Carmon et al., 2003). It also showed that the intensity of an attachment is subject to the nature of the elaboration (e.g., a narrative process or other type of process) and the context of the elaboration (e.g., the order in which an individual encounters an option). Finally, narrative persuasion was extended to evaluate more than a single object. Narrative persuasion has mostly been shown in relation to a single attitudinal target (see the meta-analysis by van Laer, de Ruyter, Visconti, \& Wetzels, 2014), ignoring the information from competitors. This study suggests that in a joint evaluation mode, narrative persuasion might strengthen or weaken depending on the order in which a consumer received marketing stimuli.

Managerially, this study suggests that companies that wish to use the serial order effect strategically should consider correspondence with information format, as a match between these two elements is likely to translate website visits into sales. A website with design elements that stimulate experiences can obtain further benefits by bidding for the topmost position in sponsored advertisements. Further, in relation to experiential goods, the order effect depends not only on a firm's creative strategy, but also the strategies of its competitors. For example, Kim et al. (2016) identified persuasion based on narrative 
transportation in the global advertising of luxury brands, including Hermes, Chanel, Louis Vuitton, and Gucci. Further, the study's findings also showed that marketers should be aware of an advertisement's serial order when placing media advertisements (e.g., in fashion magazines, or on YouTube) in the presence of competing brands.

The remainder of the paper is organized as follows. First, order effect is reviewed in relation to the evaluation of experiential options. Then, the reasons that narrative processing is likely to lead to a primacy effect in the evaluation of simulated experience are discussed. Next, it is argued that motivated reasons should be selected as the mechanism rather than the attached option, and moderators are proposed accordingly. Following this, the results of the three experiments are reported. Finally, the theoretical contributions and managerial implications of the study are expanded upon in a general discussion.

\section{THEORETICAL BACKGROUD}

\section{Serial Order in the Evaluation of Experiential Options}

Experiential products that entail somatosensory experiences have been shown to comprise sensory, affective, and informational components (Ladhari, 2007; Nagata, Dalton, Doolittle, \& Breslin, 2005; Shiv \& Nowlis, 2004). When consumers encounter a sequence of experiential options, they encode the sensory experience and attribute information to memory, and then retrieve them to make judgments on the options. As additional information enters working memory, the memory traces for the earlier options decay in working memory (Estes, 1997; Klein, Wesson, \& Hollenbeck, 1999). The sensory input from, and affective responses to, the last option remain salient and may interfere with the recall of the preceding options (Cowley, 2007). In addition, the attribute information of the last option remains salient in working memory, and is given more weight than that of the 
preceding options (Mantel \& Kardes, 1999; Neath, 1993). Consequently, the sensory, affective, and information components of the last option in a sequence have a greater impact than the components of the earlier options (Biswas et al., 2010).

Indirect experiences differ from direct experiences in mental construal and evaluative thoughts (Hamilton \& Thompson, 2007; Millar \& Millar, 1996). A direct experience is characterized by concrete sensory input, and automatic affective responses. Conversely, an indirect experience tends to form abstract mental imagery, and invite evaluative thoughts. Despite these differences, there are reasons to believe that a recency effect might occur in the evaluations of simulated experiences. Consumers use imagery salience as a heuristic when evaluating experiential options with multiple attributes (Keller \& McGill, 1994). Easy-to-image attributes have a great impact on evaluations because their imagery appears vivid and entails strong affective responses (Brakus, Schmitt, \& Zhang, 2014). Based on imagery heuristics, serial order should also influence evaluations due to imagery salience. As the mental imagery of the last option remains vivid in working memory, it should entail a stronger affective response and influence preferences more than that of the earlier options. Thus, a recency effect is likely to occur when an experience is simulated.

Narrative Processing in the Sequential Encountering of Experiential Options

However, the preceding prediction overlooks the fact that mental imagery can be a self-referencing process in a story-like manner (Escalas, 2007; Kerby, 1991). Information in a narrative format predisposes individuals to imagine that they are experiencing events (Adaval \& Wyer, 1998; Escalas, 2004). The sensory and contextual details in narrative processing enable individuals to vicariously experience the consequences of product use (Bersamin, Walker, Waiters, Fisher, \& Grube, 2005). Narrative processing has been shown to affect attitudes in single evaluations by "transporting" individuals into a hypothetical 
consumption scenario to elicit strong affective responses (Escalas, 2007; Green \& Brock, 2000; Taylor et al., 1998).

In a sequence of experiential options, a self-referencing narrative enhances the memory of simulated options and retains memory traces of these options (Krishnamurthy $\&$ Sujan, 1999). The memory of an earlier option is less prone to decay and easy to recall at a later stage. Further, mental simulation has been shown to entail pre-factual ownership, or option attachment (Carmon et al., 2003). Foregoing a self-connected option represents an aversive event (Delorme, Zinkhan, \& Hagen, 2005); thus, individuals should be motivated to ensure its attractiveness in the evaluation process. Accordingly, in addition to strengthening the sensory, affective, and information components of earlier options in working memory, narrative processing may introduce a motivational component to support an attached option.

Serial order affects the way in which a motivational component biases evaluations. Decades of research on the primacy effect have shown that individuals establish a leading option early in their evaluations (Brownstein, 2003). Carlson, Meloy, and Russo (2006) showed that in a series of unknown brands, the first option with favorable attributes became the temporarily preferred option to bias evaluation in favor of the preferred option. Leaderdriven primacy is driven by a consistency goal (Russo, Carlson, Meloy, \& Yong 2008; Russo, Meloy, \& Medvec, 1998). This goal can be so strong that individuals choose a selfidentified inferior option (Russo, Carlson, \& Meloy, 2006). Thus, an option that is simulated first in a series of favorable options may be temporarily preferred to motivate consistent evaluations. Thus, it was formally hypothesized that:

H1: The first option is more favorable when narrative processing is facilitated than when it is inhibited. 
The motivation to conduct consistent evaluations with an attached option varies among individuals (Russo et al., 2008). Some individuals adopt a belief tentatively, and update their beliefs and opinions in response to additional information (Johnson, 2009). Conversely, other individuals are impervious to information that contradicts their opinions. Once challenged, they experience negative emotions and react defensively. To avoid negative feelings, these individuals are motivated to minimize inconsistencies and commit conformation biases. Thus, a defensive attitude to a self-threat is likely to perpetuate a consistency goal in the course of an evaluation, sustaining the preference for the first option under narrative processing.

The motivation to defend an attached option may increase when the sense of threat intensifies. In addition to individual characteristics, the sense of threat may arise from product characteristics. As attractive alternatives represent strong competition to an attached option, they should entail a strong sense of threat. Converging evidence can be found in research on social evaluations. Physical attractiveness is generally the source of a positive effect that generates liking of a social target (Eagly, Ashmore, Makhijani, \& Longo, 1991); however, attached individuals see attractive social targets as threats to their relationship, and thus degrade their attractiveness (Johnson \& Rusbult, 1989; Lydon, Fitzsimons, \& Naidoo, 2003; Lydon, Meana, Sepinwall, Richards, \& Mayman, 1999; Simpson, Gangestad, \& Lerma, 1990). The sense of a threat is likely to motivate a consistent evaluation when competing options appear attractive. Thus, due to narrative processing, a preference for an attached option should increase as competing options appear to be attractive. Thus, it was hypothesized that:

H2: Due to narrative processing, a preference for the first favorable option should increase when an individual holds a defensive attitude to a self-threat or when competing options appear attractive to entail a sense of a threat. 
Figure 1 summarizes the theoretical framework. Three experiments were conducted to test the hypotheses. The first experiment tested whether narrative processing entailed a favorable attitude toward the first viewed option. In support, it showed a greater preference toward the first (vs. last) option when tour information was described in a way that facilitated (vs. inhibited) narrative processing. Next, the second experiment tested whether the preference of the first option under narrative processing was accountable by motivation to defend an attached option. To test this hypothesis, option attachment was measured and defensiveness manipulated toward options that posed a threat to the first option. The results showed that narrative processing entailed a greater attachment to the first option relative to the competing option. However, in support of the motivated reasoning explanation, this difference in attachments across the options was only apparent when a defensive attitude was activated. A final experiment was conducted to test this explanation. Specifically, defensiveness toward a competing option with a product feature (i.e., the perceived attractiveness of the competing option) was altered. The result showed that preferences for the first option under narrative processing increased as the competing option became attractive (and thus threatened the first option). Table 1 summarizes the results for the three experiments.

\author{
[Insert Figure 1 about here] \\ [Insert Table 1 about here]
}

\title{
EXPERIMEN 1
}

The first experiment sought to determine whether narrative processing moderated the order effect. A narrative conveys information in a temporally related sequence, predisposing individuals to imagine themselves in the described events in a story-like manner (Adaval \& Wyer, 1998). Conversely, information could appear in an unordered list with little indication 
of the sequence. A list format facilitates comprehension in a piecemeal fashion (Adaval, Isbell, \& Wyer, 2007). Individuals tend to store specific information in their minds and retrieve pieces of information for comparison after processing an option. Thus, presenting information in a list format inhibits narrative processing. We expected a greater preference for the first option when information was presented in narrative format than when it was presented in list format.

Pre-test

Tour packages were used as experimental stimuli. Based on a pre-test, tourist attractions in Turkey were chosen to form the tour packages. As most of the participants had not previously traveled to Turkey, the effect of direct experience was controlled. Twelve destinations were assigned to two tour packages: Package A and Package B (see Appendix). The descriptions of the attractions were presented in narrative and list format. The narrative format conveyed the trip information as a sequence of destinations. Conversely, the list format conveyed the destinations in bullet points, giving no indication of temporal relatedness. Four packages were prepared for the study: Package A and Package B in both narrative and list format. Participants were recruited to evaluate the four packages independently. They were asked to indicate the extent to which they liked the packages on a 7-point scale. The results showed that participants' overall evaluations of the four packages did not differ when they were evaluated independently (Mnarrative_A $=5.71$, Mnarrative_B $=6.00 ;$ Mlist_A $=5.50$, Mlist_B $=5.50, F(3,27)<1, p>.50)$.

\section{Design and Procedure}

Participants from an online panel were recruited to evaluate two tour packages for a small stipend. One hundred and twenty-four participants participated in the study $(51.6 \%$ male, age $=37$ years). Overall, $95.9 \%$ of the participants had not traveled to the destination previously. Participants were asked to consider two tour packages for Turkey and evaluate 
their attractiveness. They were randomly assigned to read the package information in either narrative or list format. Under the narrative (vs. list) condition, participants read one tour package in narrative format (vs. list format). Afterwards, they read the other tour package in the same format. The serial order of the two packages was counterbalanced. Thus, half of the participants read Package A followed by Package B, while the remaining half read Package B followed by Package A. Consequently, the two packages had an equal chance of being the first option encountered by participants.

After reading both packages, participants were asked to indicate their choice between the first and second options. They were then asked to report their relative preference between the options. To indicate their relative preference, participants had to rate the packages on a scale in which the mid-point, 0 , was labeled as indifference between the two packages. To the left of the mid-point were the numbers 1 to 5 ; a greater number indicated a stronger relative preference toward the first option. To the right side of the midpoint were the numbers 1 to 5; a greater number indicated a stronger relative preference toward the second option. Participants were also asked to evaluate each option on 7-point scales for likeability (i.e., how much that they liked an option), positivity (i.e., how positive their overall opinion was), pleasantness (i.e., how pleasant the package was), and anticipated satisfaction (i.e., how satisfied they would be if they were to take the vacation described in the package). Finally, participants were asked to report their age, gender, and whether they had traveled to the destinations before. After completing the experiment, participants were thanked and debriefed.

Results

Choice. The result showed the majority of the participants (i.e., 56\%) chose the last option under the list condition. Conversely, under the narrative condition, the majority shifted such that $63 \%$ of participants chose the first option, and $37 \%$ of 
participants chose the last option. The first option was significantly more likely to be selected when the information was presented in a narrative format than when it was presented in a list format (i.e., $63 \%$ vs. $44 \%, \chi^{2}(1)=4.50, p=.03$ ).

Relative preference. Table 1 summarizes the results for participants' relative preferences. The relative preference scores were recoded as values from 1 to 11 , where a mid-point score of 6 indicated indifference to the two options. A relative preference score greater (vs. lower) than 6 indicated a preference for the first (vs. last) option. The preference for the first option was significantly higher under the narrative condition than the list condition $\left(\mathrm{M}_{\text {narrative }}=6.79\right.$ vs. $\mathrm{M}$ list $\left.=5.27 . t(122)=3.24, p=.002\right)$, suggesting that a preference shift to the first option occurred due to narrative processing.

Evaluation. The four items for option likeability, positivity, pleasantness, and anticipated satisfaction were averaged $\square \square \square .96$ ); the option evaluation is reported in Table 1. Under the list condition, the last option was rated higher than the first option $\left(\mathrm{M}_{\text {first }}=5.31, \mathrm{M}\right.$ last $\left.=5.56, t(58)=2.47, p=.02\right)$. Conversely, the first option received a higher rating than the last option under the narrative condition $(\mathrm{M}$ first $=5.30, \mathrm{Mlast}=$ $5.05, t(64)=2.71, p=.01)$. The difference score between the two options across both formats were also compared. The first option was significantly more favored under the narrative condition than the list condition $\left(\mathrm{M}_{\text {narrative }}=.25 \mathrm{vs} . \mathrm{M} l i s t=-.24, t(122)=3.66\right.$, $p<.001)$. As the difference scores related the difference in evaluations between options, an analysis was conducted on the difference scores in the following studies.

\section{Discussion}

This experiment juxtaposed the list format to the narrative format and showed that the last option was more likely to be chosen, better preferred, and more favorably evaluated when the information format did not facilitate narrative processing. This recency effect is consistent with the findings of Biswas et al. (2010). Conversely, the 
first option was more often selected, better preferred, and more favorably evaluated when the information format facilitated narrative processing. The preference shift to the first option supports the moderating role of narrative processing on the order effect.

The results of the experiment provided evidence consistent with the hypotheses. However, without identifying the process underlying the preference shift, the results of the study may be open to alternative interpretations. One possible explanation for the preference shift is choice difficulty; that is, narratives make the choice task more difficult, and consequently individuals are more likely to use their first impressions as decision heuristics. To address this explanation, option attachment was measured to account for this process in the next study. A defensive attitude to a self-threat was also manipulated. It was expected that the preference shift would be prominent in individuals with defensive attitudes, but not in individuals with receptive attitudes. This prediction went against the choice difficulty explanation. A receptive attitude should presumably increase choice difficulty, as individuals are inclined to consider information inconsistent with their established preferences. If choice difficulty accounts for the preference shift, the shift should also be prominent in individuals with receptive attitudes.

\section{EXPERIMEN 2}

Experiment 2 sought to determine whether a preference shift to the first option emerged because narrative processing enhanced a personal connection to the first option that one elaborated. Specifically, in this experiment, sense of attachment across options in different serial orders was measured and contrasted. In addition, it was predicted that a preference shift to the first option would be more prominent when a defensive attitude to a self-threat was activated than when a receptive attitude was activated. Previous research on 
lay theories of personality have shown that individuals with a fixed theory of self exhibit greater defensive behaviors (i.e., behaviors designed to protect who they are when confronting information that poses threats to the self) while individuals with an incremental theory are more ready to change and embrace threats, and exhibit less defensive behaviors in response to self-threats (Dweck \& Elliott-Moskwa, 2010; Walton, Paunesku, \& Dweck, 2012). Individuals can differ in relation to their lay theories of personality, and thus so can their attitudes toward threats. These differences can also be situationally elicited (Chiu, Hong, \& Dweck, 1997). Adopting this paradigm, in this experiment, participants were primed with either a defensive or receptive attitude. The clean design of this experiment enabled the causal relationship between this individual difference and the preference shift to be established. However, it should be noted that measuring attitudes toward threats as a chronic individual difference leaves the findings of this experiment open to alternative interpretations. For example, a common third variable could explain both the variations in the individual trait and the observed effects related to the preference shift.

\section{Design and Procedure}

This study employed a two (information format: narrative vs. list) by two (attitude to threat: defensive vs. receptive) between-subjects design. One hundred and fifty participants were recruited from an online panel for a stipend (43.3 \% male, age $=34.7$ years). Overall, $97.3 \%$ of participants had not traveled to the target destination before. The study began with a comprehension task that described a fictitious war hero and his philosophy in a time of uncertainty. To prime a defensive attitude to a threat, the fictitious war hero was described as upholding the ethos of "protecting who you are" and "defending against threat" in the face of uncertainty. Under receptive attitude priming, the ethos was changed to "being ready to change" and "embracing threats." After reading the comprehension task, participants were asked to answer questions on their attitudes toward 
threat. They had to indicate their agreement with two approaches for managing uncertainty (i.e., to "be open to threat and ready to change" and to "be defensive and ready to protect oneself) on 7-point scales. These questions served as the manipulation check for a defensive attitude.

After reading the comprehension task, participants were randomly assigned to read the two tour packages in narrative or list format. As in the previous experiment, participants were presented with a first option. After they finished reading, they proceeded immediately to the second option. They were then asked to report their relative preferences and evaluations. Relative preferences and option evaluations were measured in the same way as in the previous experiment. Afterwards, participants were asked to indicate the extent to which they felt personally connected to the two packages on 11-point scales (where 0 indicated "not at all" and 10 indicated "very much"). The self-option connection measures were adopted from Park, MacInnis, Priester, Eisingerich, and Iacobucci (2010), who proposed three dimensions of product attachment: personal connection, distress resulting from option unavailability, and thought prominence.

Results

Manipulation check. Participants were more defensive and inclined to protect themselves under the defensive attitude condition (Mdefensive $=6.24$, Mreceptive $=3.59$, $F(1,148)=77.25, p<.001)$, while those under the receptive attitude condition were more open to threats $($ Mdefensive $=4.18$, Mreceptive $=6.30, F(1,148)=52.66, p<.001)$. Thus, the attitude priming was successful.

Relative preference. The main effect of the information format was significant $\left(\mathrm{M}_{\text {narrative }}=6.61, \mathrm{M}\right.$ list $\left.=5.25, F(1,146)=11.51, p<.01\right)$, suggesting that the narratives entailed greater preference to the first option than the list format. The main effect of attitude was also significant $(\mathrm{M}$ defensive $=6.40$, Mreceptive $=5.55, F(1,146)=4.35, p=.04)$; a 
defensive attitude generated a greater preference for the first option than a receptive attitude. The two-way interaction between information format and attitude was significant $(F(1,146)$ $=7.27, p=.01)$. Under the defensive attitude condition, participants showed a greater preference for the first option when information was in narrative format than when it was in list format $\left(\mathrm{M}_{\text {narrative }}=7.84, \mathrm{M}\right.$ list $\left.=5.11, F(1,146)=16.95 p<.001\right)$. The preference shift to the first option did not occur under the receptive attitude condition (Mnarrative $=$ 5.70, Mlist $=5.39, F(1,146)<1, p>.60)$. The results supported the hypothesis that the preference shift to the first option was prominent when defensiveness to a threat was active.

Evaluation. The evaluations of option likeability, positivity, pleasantness, and anticipated satisfaction were averaged ( $\square=.96)$. The evaluation of the two options is reported in Table 1. The difference in the evaluations was used for further analysis. The ANOVA analysis of the difference scores showed a significant main effect of format $\left(\mathrm{M}_{\text {narrative }}=.25, \mathrm{M}\right.$ list $\left.=-.43, F(1,146)=12.15, p=.001\right)$, and a marginally significant main effect of attitude to threats (Mdefensive $=.10$, Mreceptive $^{=-.24, F(1,146)}=3.26, p$ $=.07)$. More importantly, the interaction between attitude and information format was significant $(F(1,146)=4.00, p=.05)$. A planned contrast analysis showed that the narrative format entailed a more favorable evaluation of the first option than the list format when a defensive attitude to a threat was primed (Mnarrative. $=.72, \mathrm{M}$ list $=-.45, F(1,146)=13.75$, $p<.001)$. No favorable evaluation of the first option was evident when a receptive attitude to a threat was primed $(\mathrm{M}$ narrative $=-.09, \mathrm{Mlist}=-.41, F(1,146)=1.22, p=.27)$.

Attachment. The results for attachment are summarized in Table $1(\alpha=.81)$. A difference score was formed by subtracting the attachment to the first option from that of the second option. A positive difference score indicated a stronger attachment to the first option than the second option. The ANOVA analysis showed a significant main effect of format $\left(\mathrm{M}_{\text {narrative }}=.45, \mathrm{M}\right.$ list $\left.=-.99, F(1,146)=18.05, p<.001\right)$, indicating that the 
narrative format facilitated self-option connection. More importantly, the interaction between attitude to threat and information format was significant $(F(1,146)=7.85, p$ $=.006)$. A planned contrast showed that attachment to the first option was stronger under the narrative format than the list format when a defensive attitude to a threat was activated $\left(\mathrm{M}_{\text {narrative }}=1.31, \mathrm{M} 1\right.$ ist $\left.=-1.28, \mathrm{~F}(1,146)=22.72, p<.001\right)$, but not when a receptive attitude to a threat was activated $\left(\mathrm{M}_{\text {narrative }}=.19, \mathrm{M}_{\text {list }}=-.72, F(1,146)=1.16, p>.28\right)$.

Mediation of attachment. A mediation analysis was conducted to test whether attachment mediated relative preference. The analysis showed a significant moderated mediation (Hayes, 2012). The indirect effect of format and attitude to threat on relative preference via attachment was significant (effect $=1.81,95 \% \mathrm{CI}=[.53,3.02], \mathrm{n}=5,000)$. A separate mediation analysis was conducted to test the mediating role of attachment on evaluation. The indirect effect of format and attitude to threat on differential evaluation through attachment was significant $(\mathrm{effect}=.89,95 \% \mathrm{CI}=[.26,1.55], \mathrm{n}=5,000)$. The results from the two mediation analyses indicated that option attachment accounted for the preference shift.

\section{Discussion}

The second experiment replicated the findings of the first experiment (i.e., a preference shift occurred to the first option when the information format facilitated narrative processing). It further demonstrated that this was due to a greater attachment to the first option. Further, the preference shift only occurred when a defensive attitude to a threat was activated, but not when a receptive attitude to a threat was activated. These findings support the notion that narrative processing entails a personal connection to the first option in serial order, and rules out choice difficulty as a potential alternative explanation. To further test this explanation, the Experiment 3 directly manipulated the 
sense of threat to the self-related option by changing the attractiveness of the competing options.

\section{EXPERIMENT 3}

In this experiment, the perceived attractiveness of the subsequent option was varied to induce a strong or weak sense of threat. It was expected that a preference for the first option would increase when it was challenged by a highly attractive alternative. Pre-test, Design and Procedure

The experiment employed a one-way design in which intensity of threat (high vs. low) was the between-subject variable. The intensity of threat was induced by the perceived attractiveness of the competing option (i.e., the last option in a two-option setting). Perceived attractiveness was varied by changing the consumer rating of the second option relative to the first option while keeping the option attributes constant. This operationalization was chosen because positive consumer reviews have been shown to change perceived attractiveness without changing actual quality (Park, Lee, \& Han, 2007).

As in Experiment 2, two tour packages in narrative format were employed. Two ratings (i.e., 4 stars or 3.5 out of 5 stars) were applied to each option. Overall, four packages were formed (i.e., Package A with a 4-star rating, Package A with a 3.5-star rating, Package B with a 4-star rating, and Package B with a 3.5-star rating). A pre-test confirmed that the 4star packages were perceived as more attractive than the 3.5-star packages $(\mathrm{M} 4$-star $=6.23$, $\mathrm{M} 3.5-\mathrm{star}=5.62, t(46)=2.53, p=.02)$.

Forty-three participants were recruited from an online panel to evaluate package tours for a stipend $(51.2 \%$ male, age $=35.9$ years $)$. Of the participants, $95.3 \%$ indicated that they had never visited the destinations. Participants were randomly assigned to a highthreat condition or a low-threat condition. Under the high-threat condition, both the first 
and the second option received a 4-star rating. The presentation of the two packages was counterbalanced such that Packages A and B were shown as the first package the same number of times. Under the low-threat condition, the first option received a 4-star rating, while the second option received a 3.5-star rating. Similarly, the presentation order of the two packages was counterbalanced so that half of the participants saw Package A with 4 stars, followed by Package B with 3.5 stars, and the other half saw Package B with 4 stars followed by Package A with 3.5 stars. Thus, under the high-threat condition, the second option received a rating on par with the first option, while it received a lower rating than the first option under the low-threat condition.

After the participants read the two packages, they were asked to indicate their relative preferences, evaluate both options, and report attachment as in Experiment 2. As consumers may regard ratings as a marketing message with persuasive intent and show reactance to a highly rated option, state reactance was measured at the end of the study to rule out this explanation (Hong \& Faedda, 1996; Hong \& Page, 1989).

Results

Relative preference. Participants showed a stronger preference for the first option under the high-threat condition than the low-threat condition (MHigh_ST $=$ 8.29$, Mlow_ST $=6.35, t(41)=2.08, p=.04)$.

Evaluation. The evaluation is reported in Table 1. A difference score was computed between the first and the second options; a positive score indicated a preference for the first option. The evaluation of the first option was significantly more favorable under the high-threat condition than the low-threat condition (Mhigh_ST $=$ 1.15$, Mlow_ST $=.17, t(41)=2.29, p=.03)$.

Attachment. A difference score was computed between the first and the second option; a positive score indicated a stronger attachment to the first option $(\alpha=.70)$. 
The difference in attachment between the two options was higher under the high-threat condition than the low-threat condition (Mhigh_ST $=1.94$, Mlow_ST $=-.27$, $t(41)=2.71, p<.01)$

Mediation analysis. An analysis was conducted to test whether option attachment mediated the effect of threat intensity on relative preference and evaluation. The indirect effect of threat on relative preference through attachment was significant $($ effect $=1.81,95 \% \mathrm{CI}=[.45,3.25], \mathrm{n}=5000)$. Similarly, the mediation of differential attachment in the effect of threat on evaluation was significant (effect $=.71,95 \% \mathrm{CI}=$ $[.26,1.45], \mathrm{n}=5000)$.

Reactance. The reactance scores did not differ significantly under the high-threat and low-threat conditions (Mhigh_ST $=2.81, \mathrm{MLow} \_\mathrm{ST}=2.51, t(41)=2.28, p<.13$ ). Reactance did not have a mediating effect on relative preference or evaluation (RP: .96, $95 \% \mathrm{CI}=[-.18,1.84], \mathrm{n}=5,000)$, evaluation: $-.31,95 \%, \mathrm{CI}=[-.92, .05])$; thus, reactance was ruled out as an alternative explanation.

\section{Discussion}

Conventional wisdom suggests that preference for an option should decrease in the presence of a highly attractive alternative; however, this study found that the relative preference for the first option increased when it was paired with a highly attractive competitor. It also showed that this occurred due to differential attachments across two options. Once individuals form a sense of a personal connection to an option, the individual continues to strongly prefer the attached option even as new options become available. This occurs because consumers are motivated to defend their attached option. Given that the development of option attachment does not rely on actual ownership or actual experience, this finding implies that marketers should seek to facilitate a sense of connection in 
advertisements, especially among new and potential customers. The marketing implications are further elaborated upon in the general discussion below.

\section{GENERAL DISCUSSION}

This research examined how serial order affects the evaluation of experiential options when indirect experience constitutes the basis of evaluation. Building on the recency effect documented in the context of direct experiences (Biswas et al., 2010), this study showed that narrative processing moderates this effect in the evaluation of indirect experiences. The three experiments provided supportive evidence. Experiment 1 showed that a preference shift to the first option occurred when information facilitated narrative processing. Experiment 2 showed that the preference shift was prominent when defensiveness to a threat was activated. Further, differential attachment accounted for this preference shift. Experiment 3 demonstrated that participants displayed greater preference for the first option when it was confronted by an attractive competing option.

\section{Theoretical Contribution}

This study expanded preliminary theoretical understandings of the serial order effect and option attachment. The effect of order on preference judgments has been examined extensively (Houston et al., 1991; Mantel \& Kardes, 1999; Hogarth \& Einhorn, 1992; Jones \& Goethals, 1987). However, this study introduced an additional factor (i.e., option attachment) to account for the primacy effect in the choice of an experiential option. The information format facilitative of experience simulation can engender an attachment being formed to the option that individuals view first and motivate a preferential evaluation for that option in the course of elaboration. The finding is consistent with the notion that consumers make choices or construct attitudes due to ego defensiveness (Jain \& Maheswaran, 2000). 
This study also extended understandings of the influence of option attachment from the pre-decision to the post-decision stage. Option attachment has been shown to affect post-choice satisfaction in the choice context of two simultaneously presented options (Carmon et al., 2003). Specifically, consumers develop a sense of pre-factual possession to choice options as they deliberate about which option to select. Once they select an option, they can no longer think of themselves as potentially owning the nonchosen option. This induces a sense of loss that manifests as post-choice discomfort and increases the appeal of the forgone option. Thus, if consumers were to closely deliberate on all options in a choice set, they may feel equally attached to each option at the predecision stage. This could lead to greater choice difficulty, which in turn decreases consumers' post-choice satisfaction. Conversely, this study showed that serial order affects the relative strength of attachments in pre-choice evaluations; thus, simplifying decisions to the strongly attached option. The results suggest that, in comparison to simultaneous presentation, close deliberation in sequential evaluations can increase postchoice satisfaction. Future studies should consider whether presentation methods make a difference in consumers' post-choice satisfaction levels.

Finally, this study contributed to the formation of leading options from the perspective of self-option relation. Previous research has shown that a leading brand naturally emerges early in most choices, and that consumers tend to construct preferences that support that leading brand (Brownstein, 2003; Carlson et al., 2006). It has been shown that biased predecisional processing is not merely a harmless tactic for augmenting confidence, but also leads to nonnormative choices of inferior alternatives. Empirically, the installation of a leading option can be achieved by showing an option as the first option (Carlson et al., 2006; Russo et al., 2006) that has greater product benefits or price 
advantages (Carlson, Meloy, \& Lieb, 2009). This study suggests that experience simulation that relates an option to the self can thus install a leading option.

\section{Practical Implications}

The theoretical reasoning is not limited to specific products; however, this study's research findings are particularly relevant to the tourism and hospitality industry, as the empirical investigation was conducted in this industry. In this section, two implications for tourism marketing are discussed. First, many companies bid for the top-most position in sponsored advertisements. However, such bidding strategies may incur a high cost per click, and are only profitable if the visits to websites are successfully converted into real purchases (Agarwal et al., 2011). To effectively manage the conversion process, the findings suggest that companies should take into consideration the correspondence between serial order and information format. As it appears that attempting to match the two components is more important than merely trying to occupy the first place in a viewer's sight. Thus, marketers seeking to capitalize on the primacy effect derived by the top position also need to ensure that the website content is facilitative of experience simulation. Marketers must decide whether to facilitate overall experience stimulation via storytelling, videos, or other methods that relate a product to the self in different ways (Krishnamurthy \& Sujan, 1999).

The findings also have implication for the display sequences on travel websites and mobile applications. For example, Tourism New Zealand's website presents activity themes such as wildlife, hiking, and adrenaline thrills on one page from left-to-right, and a narrative description of the travel plan is available upon clicking. When accessing the same information on a mobile phone, these activities are presented vertically and users need to scroll down to view the options sequentially. As individuals read information consistent with the dominant reading direction, websites should prioritize the activity 
packages that they are seeking to grow placing them in the first location on the screen across different digital platforms.

Finally, this study examined narrative persuasions in a sequential evaluation. Narrative processing uses narrative transportation to persuade individuals by making them become "lost in the story." Narrative persuasion is distinctive from analytical persuasion, as it is based on affective responses rather than cognitive evaluations (Escalas, 2007). The majority of research on narrative persuasion has examined attitudes toward one evaluation target (see van Laer et al.’s 2014 meta-analysis) without considering information from competitors. Conversely, this study showed that the persuasiveness of a narration weakens if it appears after another narration. Presently, many luxury brands attempt to influence brand attitudes through narrative transportation (Kim et al., 2016). However, this approach may be more effective when it is placed before a competitor advertisement that uses the same creative strategy. Thus, marketers should monitor competitor's advertisements on social media platforms (e.g., YouTube) and ensure that their advertisements are placed so that they will be shown before their competitors' advertisements.

In addition to the marketing communication of tour packages, the findings of this study have two implications for the product category in which consumers seek an experience at the market level. First, the findings support a "first mover" advantage in the product categories where consumption is driven by experience seeking. The first option with which consumers form a personal connection is likely to be strongly preferred when competing options are available on the market. A sense of personal connection does not require ownership. Consistent with Brakus, Schmitt, and Zarantonello (2009), the findings of this study suggest that a new product could benefit from inviting consumers to image a new experience that fosters a personal connection. Once a personal connection with a product has been established, the promotional messages from competing options may serve 
as cues to strengthen the established preference. The findings also showed that the stronger the competitor, the more likely consumers are to engage in motivated reasoning to defend their established preference.

Second, this study showed that the degree to which consumers engage in motivated reasoning in favor of a leading option/brand is related to their tendency to be defensive to self-threats. This finding suggests that the primacy effect is prominent among individuals whose personality are high in dogmatism or low in openness to new experience. Conversely, these finding imply that a brand competing with a leading brand in the market should target consumers who are lowly dogmatic or highly open to new experiences and seek to persuade them via the analytic route of persuasion (e.g., superior value for money).

\section{Limitations and Future Studies}

One limitation of this study is that it focused on experience seeking travelers; however, many consumers also travel for utilitarian purposes such as business trips. Research has shown that experiential products have qualities similar to material products when utilitarian benefits are highlighted (Guevarra \& Howell, 2015). This study's findings inform situations in which experiential benefits are highlighted. Future studies should examine situations in which the consumption motive for travel is not experience seeking.

In addition, this study only focused on experiences of which individuals had limited previous exposure. Many products and service providers offer an experience that while not entirely new is somewhat different to a previous experience (e.g., a Hello-Kitty-themed flight, or a new facility in an existing theme park). For these types of product, previous experience may ease imagination in a consumption episode. If this occurs, the primacy effect demonstrated in the existing research should hold. However, a previous experience could also inform attribute importance, and direct attention to weighing attributes rather than 
generating mental imagery. Given these possibilities, future research should investigate the effects of previous experiences.

Finally, future research should seek to extend this study's framework beyond consumption decisions to social marketing. Attitudes toward social issues (e.g., climate change, immigration, globalization, and gun ownership) are becoming increasingly polarized. Narratives have been shown to be persuasive through the affective route; however, it is unclear whether the use of narratives could trigger motivated reasoning that could be used to defend an established attitude toward a social issue. Thus, future research should compare and contrast the affective route of persuasion with the cognitive route of persuasion in attitude changes for social issues. 


\section{REFERENCES}

Adaval, R. \& Wyer, R. S. (1998). The role of narratives in consumer information processing. Journal of Consumer Psychology, 7(3), 207-245. http://doi.org/10.1207/s15327663jcp0703_01

Adaval, R., Isbell, L. M., \& Wyer, R. S. (2007). The impact of pictures on narrative- and listbased impression formation: A process interference model. Journal of Experimental Social Psychology, 43(3), 352-364. http://doi.org/10.1016/j.jesp.2006.04.005

Agarwal, A., Hosanagar, K., \& Smith, M. D. (2011). Location, location, location: An analysis of profitability of position in online advertising markets. Journal of Marketing Research, 48(6), 1057-1073. https://doi.org/10.1509/jmr.08.0468

American Express. (2015). American Express travel: Future travel trends. Retrieved from http://about.americanexpress.com/news/pr/2015/amex-travel-100-years-service.aspx

Anderson, C. A. (1983). Behavioral scripts on personal intentions. Journal of Personality and Social Psychology, 45(2), 293-305.

Ardelet, C., Slavich, B., \& de Kerviler, G. (2015). Self-referencing narratives to predict consumers' preferences in the luxury industry: A longitudinal study. Journal of Business Research, 68(9), 2037-2044. http://doi.org/10.1016/j.jbusres.2015.02.017

Bersamin, M. M., Walker, S., Waiters, E. D., Fisher, D. A., \& Grube, J. W. (2005). Promising to wait: Virginity pledges and adolescent sexual behavior. Journal of Adolescent Health, 36(5), 428-436. https://doi.org/10.1016/j.jadohealth.2004.09.016

Biswas, D., Grewal, D., \& Roggeveen, A. (2010). How the order of sampled experiential products affects choice. Journal of Marketing Research, 47(3), 508-519. http://doi.org/10.1509/jmkr.47.3.508

Bone, P. F. \& Ellen, P. S. (1992). The generation and consequences of communication-evoked imagery. Journal of Consumer Research, 19(1), 93-104. http://doi.org/10.1086/209289

Brakus, J. J., Schmitt, B. H., \& Zarantonello, L. (2009). Brand experience: What is it? How is it measured? Does it affect loyalty? Journal of Marketing, 73(May), 52-68.

http://doi.org/10.1509/jmkg.73.3.52 
Brakus, J. J., Schmitt, B. H., \& Zhang, S. (2014). Experiential product attributes and preferences for new products: The role of processing fluency. Journal of Business Research, 67(11), 2291-2298. http://doi.org/10.1016/j.jbusres.2014.06.017

Brownstein, A. L. (2003). Biased predecision processing. Psychological Bulletin, 129(4), 545568. http://doi.org/10.1037/0033-2909.129.4.545

Carlson, K. A., Meloy, M. G., \& Lieb, D. (2009). Benefits leader reversion: How a oncepreferred product recaptures its standing. Journal of Marketing Research, 46, 788-797. https://doi.org/10.1509/jmkr.46.6.788

Carlson, K. A., Meloy, M. G., \& Russo, J. E. (2006). Leader-driven primacy: Using attribute order to affect consumer choice. Journal of Consumer Research, 32(3), 513-518. http://doi.org/10.1086/500481

Carmon, Z., Wertenbroch, K., \& Zeelenberg, M. (2003). Option attachment: When deliberating makes choosing feel like losing. Journal of Consumer Research, 30(1), 15-29. http://doi.org/10.1086/374701

Carroll, J. S. (1978). The effect of imagining an event on expectations for the event: An interpretation in terms of the availability heuristic. Journal of Experimental Social Psychology, 14(1), 88-96. http://doi.org/10.1016/0022-1031(78)90062-8

Carter, T. J. \& Gilovich, T. (2010). The relative relativity of material and experiential purchases. Journal of Personality and Social Psychology, 98(1), 146-159. http://doi.org/10.1037/a0017145

Carter, T. J. \& Gilovich, T. (2012). I am what I do, not what I have: The differential centrality of experiential and material purchases to the self. Journal of Personality and Social Psychology, 102(6), 1304-1317. http://doi.org/10.1037/a0027407

Chan, T. Y., \& Park, Y.-H. (2015). Consumer search activities and the value of ad positions in sponsored search advertising. Marketing Science, 34(4), 606-623. https://doi.org/10.1287/mksc.2015.0903 
Chang, C. (2012). The role of ad-evoked consumption visions in predicting brand attitudes: A relevancy principle model. Psychology and Marketing, 29(12), 956-967. http://doi.org/10.1002/mar.20577

Chiu, C. Y., Hong, Y. Y., \& Dweck, C. S. (1997). Lay dispositionism and implicit theories of personality. Journal of Personality and Social Psychology, 73(1), 19-30. https://doi.org/10.1037/0022-3514.73.1.19

Cowley, E. (2007). How enjoyable was it? Remembering an affective reaction to a previous consumption experience. Journal of Consumer Research, 34(4), 494-505. http://doi.org/10.1086/520072

Davies, M. F. (1998). Dogmatism and belief formation: Output interference in the processing of supporting and contradictory cognitions. Journal of Personality and Social Psychology, 75(2), 456-466. http://doi.org/10.1037/0022-3514.75.2.456

Delorme, D. E., Zinkhan, G. M., \& Hagen, S. C. (2005). The process of consumer reactions to possession threats and losses in a natural disaster. Marketing Letters, 15(4), 185-199. http://doi.org/10.1007/s11002-005-0456-Z

Dweck, C. S. \& Elliott-Moskwa, E. S. (2010). Self-theories: The roots of defensiveness. Social Psychological Foundations of Clinical Psychology, 136-153.

Dykins, R. (2015). Shaping the future of luxury travel: Future traveller tribes 2030. Retrieved from http://www.amadeus.com/documents/future-traveller-tribes-2030/luxurytravel/shaping-the-future-of-luxury-travel-report.pdf

Eagly, A. H., Ashmore, R. D., Makhijani, M. G., \& Longo, L. C. (1991). What is beautiful is good, but...A meta-analytic review of research on the physical attractiveness stereotype. Psychological Bulletin, 110(1), 109-128. http://doi.org/10.1037/0033-2909.110.1.109

Escalas, J. E. (2004). Imagine yourself in the product: Mental simulation, narrative transportation, and persuasion. Journal of Advertising, 33(2), 37-48. http://doi.org/10.1080/00913367.2004.10639163 
Escalas, J. E. (2004). Narrative processing: Building consumer connections to brands. Journal of Consumer Psychology, 14(1-2), 168-180. https://doi.org/10.1207/s15327663jcp1401\&2_19

Escalas, J. E. (2007). Self-referencing and persuasion: narrative transportation versus analytical elaboration. Journal of Consumer Research, 33(4), 421-429. http://doi.org/10.1086/510216

Estes, W. K. (1997). Processes of memory loss, recovery, and distortion. Psychological Review, 104(1), 148-169. http://doi.org/10.1037/0033-295X.104.1.148

Google. (2014). Travelers' use of the Internet. Retrieved from https://storage.googleapis.com/think/docs/2014-travelers-road-todecision_research_studies.pdf

Green, M. C. (2008). Transportation Theory. In International Encyclopedia of Communication (pp. 5170-5175). https://doi.org/10.1111/b.9781405131995.2008.x

Green, M. C. \& Brock, T. C. (2000). The role of transportation in the persuasiveness of public narratives. Journal of Personality and Social Psychology, 79(5), 701-721. http://doi.org/10.1037/0022-3514.79.5.701

Gregory, W. L., Cialdini, R. B., \& Carpenter, K. M. (1982). Self-relevant scenarios as mediators of likelihood estimates and compliance: Does imagining make it so? Journal of Personality and Social Psychology, 43(1), 89-99. http://doi.org/10.1037/00223514.43.1.89

Guevarra, D. A. \& Howell, R. T. (2015). To have in order to do: Exploring the effects of consuming experiential products on well-being. Journal of Consumer Psychology, 25(1), 28-41. http://doi.org/10.1016/j.jcps.2014.06.006

Hamilton, R. W. \& Thompson, D. V. (2007). Is there a substitute for direct experience? Comparing consumers' preferences after direct and indirect product experiences. Journal of Consumer Research, 34(4), 546-555. http://doi.org/10.1086/520073

Hayes, A. F. (2012). Process: A versatile computational tool for observed variable mediation, moderation, and conditional process modeling. In A. F. Hayes (Ed.), An Introduction to 
Mediation, Moderation, and Conditional Process Analysis: A Regression-based Approach (pp. 1-39). New York, NY: Guildford Press.

Hogarth, R. M. \& Einhorn, H. J. (1992). Order effects in belief updating: The belief-adjustment model. Cognitive Psychology, 24(1), 1-55. http://doi.org/10.1016/0010-0285(92)90002-J

Holbrook, M. B., \& Hirschman, E. C. (1982). The experiential aspects of consumption: Consumer fantasies, feelings, and fun. Journal of Consumer Research, 9(2), 132-140. https://doi.org/10.1086/208906

Hong, S.-M. \& Faedda, S. (1996). Refinement of the Hong psychological reactance scale. Educational and Psychological Measurement, 56(1), 173-182. http://doi.org/10.1177/0013164496056001014

Hong, S.-M. \& Page, S. (1989). A psychological reactance scale: Development, factor structure and reliability. Psychological Reports, 64(3), 1323-1326. http://doi.org/10.2466/pr0.1989.64.3c.1323

Houston, D. A., Sherman, S. J., \& Baker, S. M. (1989). The influence of unique features and direction of comparison of preferences. Journal of Experimental Social Psychology, 25(2), 121-141. http://doi.org/10.1016/0022-1031(89)90008-5

Houston, D. A., Sherman, S. J., \& Baker, S. M. (1991). Feature matching, unique features, and the dynamics of the choice process: Pre-decision conflict and post-decision satisfaction. Journal of Experimental Social Psychology, 27(5), 411-430.

Howard, M. W., \& Kahana, M. J. (1999). Contextual variability and serial position effects in free recall. Journal of Experimental Psychology. Learning, Memory, and Cognition, 25(4), 923-941.

Hung, I. W., \& Mukhopadhyay, A. (2012). Lenses of the heart: How actors' and observers' perspectives influence emotional experiences. Journal of Consumer Research, 38(6), 1103-1115. http://doi.org/10.1086/661529

Jain, S. P., \& Maheswaran, D. (2000). Motivated reasoning: A depth-of-processing perspective. Journal of Consumer Research, 26, 358-371. https://doi.org/10.1086/209568 
Johnson, D. J. \& Rusbult, C. E. (1989). Resisting temptation: Devaluation of alternative partners as a means of maintaining commitment in close relationships. Journal of Personality and Social Psychology, 57(6), 967-980. http://doi.org/10.1037/00223514.57.6.967

Johnson, J. J. (2009). What's so wrong with being absolutely right: The dangerous nature of dogmatic belief. New York, NY: Prometheus Books.

Jones, E. E. \& Goethals, G. R. (1987). Order effects in impression formation: Attribution context and the nature of the entity. In Attribution: Perceiving the causes of behavior (pp. 27-46). Hillsdale, NJ: Lawrence Erlbaum Associates.

Keller, P. A. \& McGill, A. L. (1994). Differences in the relative influence of product attributes under alternative processing conditions: Attribute importance versus attribute ease of imagability. Journal of Consumer Psychology, 3(1), 29-49. http://doi.org/10.1016/S1057-7408(08)80027-7

Kerby, A. P. (1991). Narrative and the self (Vol. 22). Bloomington: Indiana University Press.

Kim, J. E., Lloyd, S., \& Cervellon, M. C. (2016). Narrative-transportation storylines in luxury brand advertising: Motivating consumer engagement. Journal of Business Research, 69(1), 304-313. http://doi.org/10.1016/j.jbusres.2015.08.002

King, D. (2014). Report finds agents losing ground to online, mobile bookings. Retrieved from http://www.travelweekly.com/Travel-News/Travel-Agent-Issues/Report-finds-agentslosing-ground-to-online-and-mobile-bookings

Klein, H. J., Wesson, M. J., \& Hollenbeck, J. R. (1999). Goal commitment and the goal-setting process: Conceptual clarification and empirical synthesis. Journal of Applied Psychology, 84(6), 885-896.

Krishnamurthy, P. \& Sujan, M. (1999). Retrospection versus anticipation: The role of the ad under retrospective and anticipatory self-referencing. Journal of Consumer Research, 26(1), 55-69. http://doi.org/10.1086/209550 
Ladhari, R. (2007). The movie experience: A revised approach to determinants of satisfaction. Journal of Business Research, 60(5), 454-462. http://doi.org/10.1016/j.jbusres.2006.12.007

Lonsway, B. (2013). Making leisure work: Architecture and the experience economy. making leisure work: architecture and the experience economy. https://doi.org/10.4324/9781315881447

Lydon, J. E., Fitzsimons, G. M., \& Naidoo, L. (2003). Devaluation versus enhancement of attractive alternatives: A critical test using the calibration paradigm. Personality and Social Psychology Bulletin, 29(3), 349-359. http://doi.org/10.1177/0146167202250202

Lydon, J. E., Meana, M., Sepinwall, D., Richards, N., \& Mayman, S. (1999). The commitment calibration hypothesis: When do people devalue attractive alternatives? Personality and Social Psychology Bulletin, 25(2), 152-161.

http://doi.org/10.1177/0146167299025002002

MacInnis, D. J. \& Price, L. L. (1987). The role of imagery in information processing: Review and extensions. Journal of Consumer Research, 13(4), 473-491. http://doi.org/10.1086/209082

Mantel, S. P. \& Kardes, F. R. (1999). The role of direction of comparison, attribute-based processing, and attitude-based processing in consumer preference. Journal of Consumer Research, 25(4), 335-352.

Millar, M. \& Millar, K. (1996). The effects of direct and indirect experience on affective and cognitive responses and the attitude-behavior relation. Journal of Experimental Social Psychology, 32(6), 561-579. http://doi.org/10.1006/jesp.1996.0025

Moore, D. T. (2010). Critical thinking and intelligence analysis. Intelligence. Berkshire, England: Books Express Publishing.

Nagata, H., Dalton, P., Doolittle, N., \& Breslin, P. S. (2005). Psychophysical isolation of the modality responsible for detecting multimodal stimuli: a chemosensory example. Journal of Experimental Psychology. Human Perception and Performance, 31(1), 101-109. http://doi.org/10.1037/0096-1523.31.1.101 
Neath, I. (1993). Contextual and distinctive processes and the serial position function. Journal of Memory and Language, 32(6), 820-840. http://doi.org/10.1006/jmla.1993.1041

Park, C. W., MacInnis, D. J., Priester, J., Eisingerich, A. B., \& Iacobucci, D. (2010). Brand attachment and brand attitude strength: Conceptual and empirical differentiation of two critical brand equity drivers. Journal of Marketing, 74(6), 1-17. http://doi.org/10.1509/jmkg.74.6.1

Park, D.-H., Lee, J., \& Han, I. (2007). The effect of on-line consumer reviews on consumer purchasing intention: The moderating role of involvement. International Journal of Electronic Commerce, 11(4), 125-148. http://doi.org/10.2753/JEC1086-4415110405

Phillips, D. M., Olson, J. C., \& Baumgartner, H. (1995). Consumption visions in consumer decision making. In F. R. Kardes \& M. Sujan (Eds.), Advances in Consumer Research (pp. 280-284). Association for Consumer Research.

Polkinghorne, D. E. (1991). Narrative and self-concept. Journal of Narrative and Life History, 1(3), 135-153.

Russo, J. E., Carlson, K. A, Meloy, M. G., \& Yong, K. (2008). The goal of consistency as a cause of information distortion. Journal of Experimental Psychology: General, 137(3), 456-470. http://doi.org/10.1037/a0012786

Russo, J. E., Carlson, K. A., \& Meloy, M. G. (2006). Choosing an inferior alternative. Psychological Science, 17(10), 899-904. http://doi.org/10.1111/j.14679280.2006.01800.x

Russo, J. E., Meloy, M. G., \& Medvec, V. H. (1998). Predecisional distortion of product information. Journal of Marketing Research, 35(4), 438-452.

Schmitt, B. (1999). Experiential marketing. Journal of Marketing Management, 15(June), 5367. https://doi.org/10.1362/026725799784870496

Shiv, B. \& Huber, J. (2000). The impact of anticipating satisfaction on consumer choice. Journal of Consumer Research, 27(2), 202-216. 
Shiv, B., \& Nowlis, S. M. (2004). The effect of distractions while tasting a food sample: The interplay of informational and affective components in subsequent choice. Journal of Consumer Research, 31(December), 599-608. http://doi.org/10.1086/425095

Shun, Y. L., Chau, A. W. L., \& Tsunhin, J. W. (2007). Thumbnails as online product displays: How consumers process them. Journal of Interactive Marketing, 21(1), 36-59. https://doi.org/10.1002/dir.20073

Simpson, J. A., Gangestad, S. W., \& Lerma, M. (1990). Perception of physical attractiveness: Mechanisms involved in the maintenance of romantic relationships. Journal of Personality and Social Psychology, 59(6), 1192-1201. http://doi.org/10.1037/00223514.59 .6 .1192

Taylor, S. E., Pham, L. B., Rivkin, I. D., \& Armor, D. A. (1998). Harnessing the imagination. Mental simulation, self-regulation, and coping. The American Psychologist, 53(4), 429439. http://doi.org/10.1037/0003-066X.53.4.429

Van Boven, L. \& Gilovich, T. (2003). To do or to have? That is the question. Journal of Personality and Social Psychology, 85(6), 1193-1202. http://doi.org/10.1037/00223514.85.6.1193

van Laer, T., de Ruyter, K., Visconti, L. M., \& Wetzels, M. (2014). The extended transportation-imagery model: A meta-analysis of the antecedents and consequences of consumers' narrative transportation. Journal of Consumer Research, 40(5).

Walker, B. A., \& Olson, J. C. (1997). The activated self in consumer behavior: A cognitive structure perspective. Research in Consumer Behavior, 8, 135-172.

Walton, G. M., Paunesku, D., \& Dweck, C. S. (2012). Expandable selves. In J. P. T. Mark R. Leary (Ed.), Handbook of Self and identity (2nd ed., pp. 141-154). New York, NY: Guilford Press.

Xiang, Z. A., Wang, D. B., O'Leary, J. T. ., \& Fesenmaier, D. R. . (2015). Adapting to the internet: Trends in travelers' use of the web for trip planning. Journal of Travel Research, 54(4), 511-527. https://doi.org/10.1177/0047287514522883 
Yoo, J., \& Kim, M. (2014). The effects of online product presentation on consumer responses:

A mental imagery perspective. Journal of Business Research, 67(11), 2464-2472.

http://doi.org/10.1016/j.jbusres.2014.03.006 


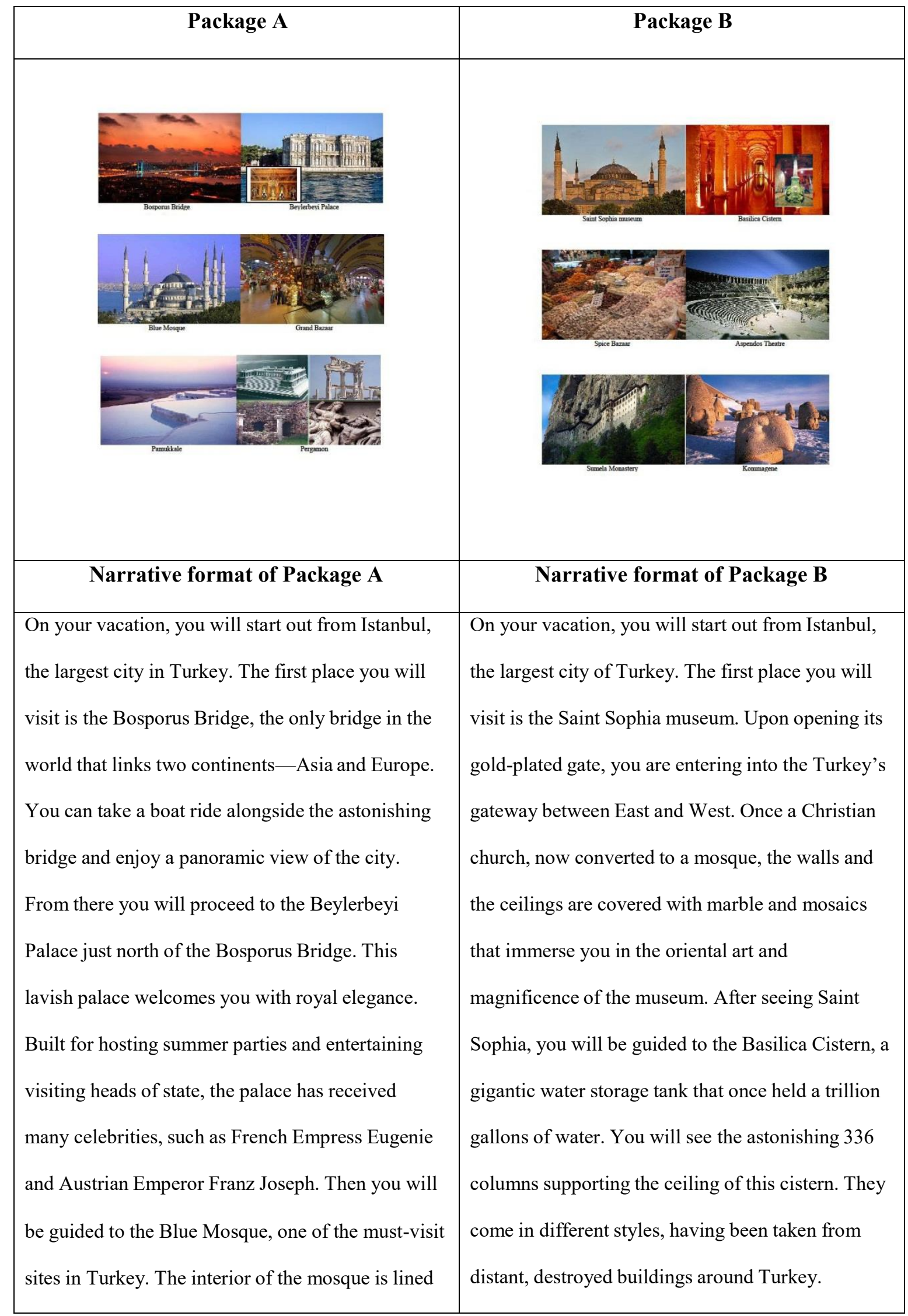


with more than 20,000 handmade ceramic tiles in more than 50 different tulip designs. You can take off your shoes and go inside, take a quiet walk and sit down on the carpeted floor, hear the silence, look up at the thousand lamps. After seeing the Blue Mosque, you will go to the Grand Bazaar, the oldest and largest covered bazaar in the world. The sheer size of the bazaar is unimaginable unless you experience it for yourself. You can spend rest of the day looking for the exquisite oriental pieces that you only find in Turkey.

The next stop after exploring the city of Istanbul is the natural wonder of Pammukale. The landscape of Pammukale makes it look as if it is made entirely out of snow, clouds or cotton balls. In fact, Pammukale means 'Cotton Castle' in Turkish. About 8,860 feet long and 600 feet wide, the expansive field offers a breath-taking view. Leaving Pammukale, you will fly to the last destination of your trip around noon-Pergamon. Pergamon was the political and cultural center of a large kingdom in the Byzantine period. You will see the ruins of a gigantic ancient library, the three temples dedicated to the worship of Roman emperors, another for the goddess Athena and the great altar of Zeus. You can spend rest of the day here and complete your trip at Pergamon.
Remember to check out the giant carved Medusa

heads at the column bases! From there, you will

proceed to the famous Spice Bazaar in Istanbul.

You will see spices in a myriad of colors and smell

their delicate scents. They will tantalise your

senses.

After exploring these interesting places in Istanbul, you will then fly to Antalya to see the Aspendos

Theatre, the best preserved Roman theatre in

Turkey. The beauty of the theatre will transport you back to ancient times, allowing you to imagine

what it was like to attend a dramatic performance in this imposing structure. Next, you will fly west to see the natural beauty of the Sumela Monastery. It is located on a steep mountainside, high above the forests. You can walk along a scenic narrow path to the monastery, from where you can enjoy the view and the beautiful valley beneath. The next stop is Kommagene, also called the 'Forgotten Kingdom'. You will arrive in Kommagene in the afternoon and enjoy the unique sunset there. Kommagene is notable for a collection of huge statues of gods and goddesses. Viewing theses statues at sunset is an unforgettable and unique memory only Turkey can offer.

\section{List format of Package A




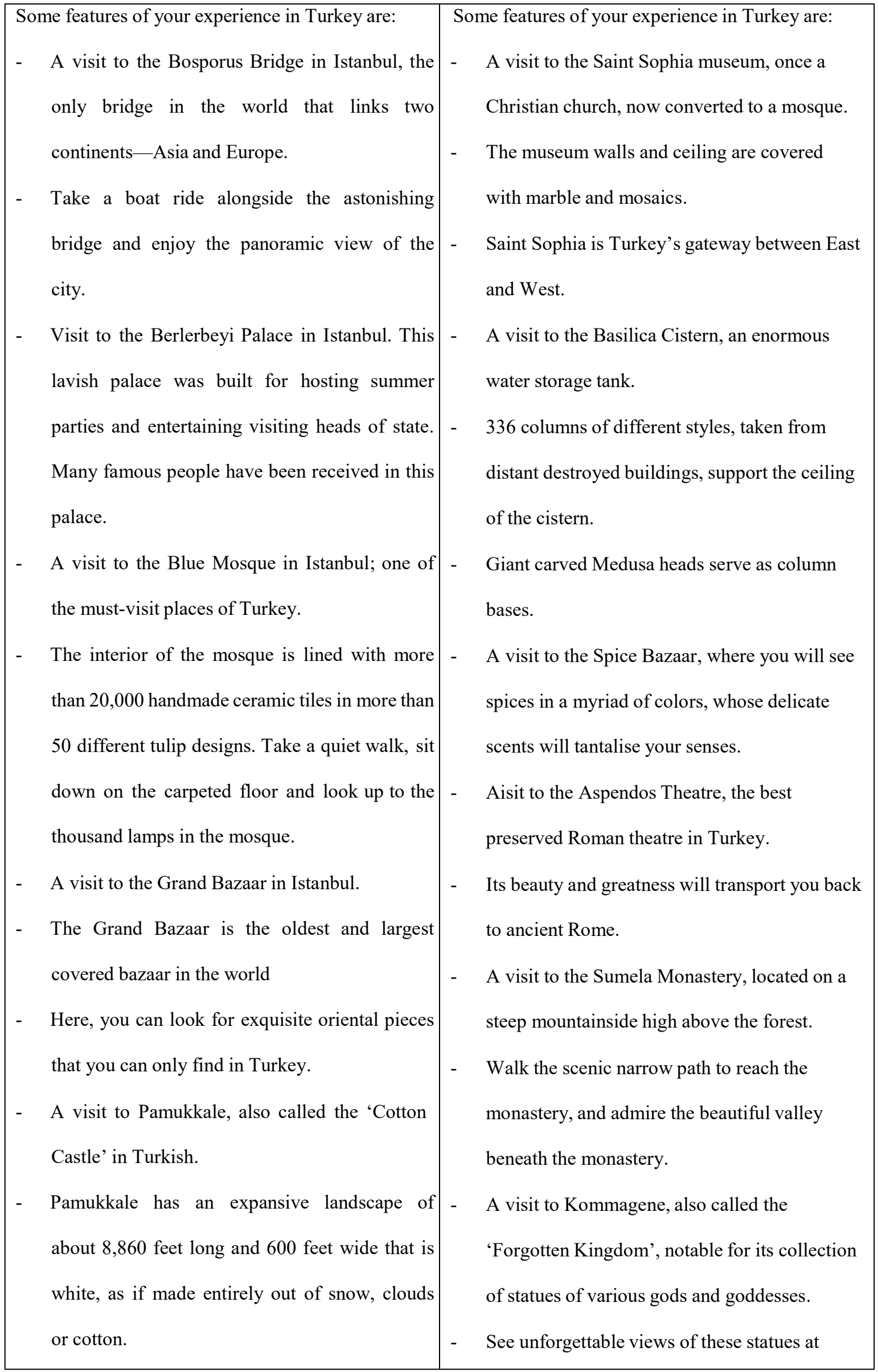




- A visit to Pergamon, the political and cultural
center of a large kingdom in the Byzantine
period.
- See ruins of a huge ancient library, the three
temples dedicated to the worship of Rome
emperors, another for goddess Athena and the
great altar of Zeus.

